\title{
FATIGUE RELIABILITY EVALUATION FOR COMPOSITE LAMINATES VIA A DIRECT NUMERICAL INTEGRATION TECHNIQUE
}

\author{
T. Y. KAM, K. H. CHU and S. Y. TSAI \\ Mechanical Engineering Department, National Chiao Tung University, 1001 Ta Hsueh Road, \\ Hsin Chu 30050, Taiwan, 300 Republic of China
}

(Received 15 October 1996; in revised form 8 April 1997)

\begin{abstract}
A direct numerical integration technique for evaluating fatigue reliability of composite laminates under varying stress amplitudes is presented. A number of cumulative damage models are adopted to construct the limit state equation for the laminates in the reliability analysis. Existing fatigue life distributions of composite laminates under cyclic stresses of constant amplitude are used in the reliability assessment of the composite laminates under varying stress amplitudes. The accuracy of the proposed method in fatigue reliability prediction is then verified by experimental fatigue life data of varying stress amplitudes. A comparison between the present method and the modified $\beta$-method is also made to illustrate the suitability of the present method in fatigue reliability prediction. 1998 Elsevier Science Ltd.
\end{abstract}

\section{INTRODUCTION}

Laminated composite materials have become an important engineering material in the construction of high performance structures such as mechanical, automotive, marine and aerospace structures in the past decade. In general, these structures are of high reliability, but susceptible to fatigue failure. The fatigue reliability of laminated composite materials has thus drawn close attention and become an important topic of research in recent years. Many efforts have been devoted to the study of fatigue life scattering and a number of probabilistic models have been proposed for modelling fatigue life distributions [e.g. Johnsen and Doner (1981); Han and Hamddi (1983); Yang et al. (1992)]. It is not difficult to realize that the previous studies have been mainly concentrated on laminates subjected to a cyclic stress of constant amplitude. For instance, Radhakrishnan (1984) used Weibull distribution to study the fatigue life of composite material specimens with zero degree fiber angle after proof test. As for fatigue reliability of materials subjected to spectrum stress, only limited work has been done in this area. For instance, Collins (1981) used cumulative damage rules and probabilistic S-N curves to study fatigue reliability of materials under spectrum stress. Yang and Du (1983) used a statistical model, which was constructed on the basis of a fatigue and residual strength degradation model for constant amplitude cyclic loading, to study fatigue life distribution of composite materials subject to service loading spectra. Recently, the authors have studied the multi-stress level fatigue reliability of composite laminates via both analytical and experimental approaches. Experimental investigation of fatigue life distribution of $\left[45^{\circ} /-45_{2} / 45^{\circ}\right]_{\mathrm{s}}$ composite specimens under varying stress amplitudes was performed and the modified $\beta$-method was used to predict the fatigue reliability of the laminates. In this paper, a direct numerical integration technique is used to predict the fatigue reliability of composite laminates under varying stress amplitudes. The previously obtained experimental fatigue life data are used to validate the present method. A comparison between the present method and the modified $\beta$-method is made to demonstrate the suitability of the present method in fatigue reliability prediction.

\section{CUMULATIVE DAMAGE MODELS}

Fatigue damage of composite materials depends on many factors such as applied stress level, number of fatiguc cycles, frequency, temperature, etc. Without loss of generality, only 
the effects of applied stress level and number of fatigue cycles on fatigue damage are considered in this study. The damage can then be written in a functional form as

$$
D=F(n, r)
$$

where $n$ is number of stress cycles; $r$ is stress ratio.

$$
r=\frac{S_{\max }}{S_{\mathrm{u}}}
$$

where $S_{\max }$ is the maximum value of the applied stress; $S_{\mathrm{u}}$ is the ultimate stress. For a constant amplitude stress, the damage is bounded by the following conditions:

$$
\begin{array}{ll}
D=0 & \text { when } n=0 \\
D=1 & \text { when } n=N
\end{array}
$$

where $N$ is fatigue life cycle under cyclic stress of constant amplitude.

Different cumulative damage models, namely Palmgren-Miner's rule, modified Palmgren-Miner's rule, Hwang-Han's model I (H-H-I) and Hwang-Han's model II (H$\mathrm{H}-\mathrm{II}$ ), are adopted in the following fatigue reliability analysis of composite laminates. The fatigue damages of two and three-stress levels for the adopted cumulative damage models are given as follows (Kam et al., 1997).

\subsection{Two-stress level}

(a) Palmgren-Miner's rule

$$
D=\frac{n_{1}}{N_{1}}+\frac{n_{2}}{N_{2}}
$$

where $n_{i}, N_{i}$ are applied stress cycles and fatigue life at the $i$ th stress level, respectively.

(b) Modified Palmgren-Miner's rule

$$
D=\left(\frac{n_{1}}{N_{1}}+\frac{n_{2}}{N_{2}}\right)^{c}
$$

where $C$ is a constant

(c) $\mathrm{H}-\mathrm{H}-\mathrm{I}$

$$
D=\frac{B-N_{1}^{\mathrm{C}}}{B-n_{1}^{\mathrm{C}}}+\frac{B-N_{2}^{\mathrm{C}}}{B-\left(n_{12}+n_{2}\right)^{\mathrm{C}}}-\frac{B-N_{2}^{\mathrm{C}}}{B-n_{12}^{\mathrm{C}}}
$$

with

$$
n_{12}=\left\{B\left[1-\left(\frac{r_{2}}{r_{1}}\right)\left(1-\frac{n_{1}^{\mathrm{C}}}{B}\right)\right]\right\}^{1 / \mathrm{C}}
$$

where $B$ is a constant.

(d) $\mathrm{H}-\mathrm{H}-\mathrm{II}$

$$
D=\left(\frac{n_{1}}{N_{1}}\right)^{\mathrm{C}}\left[\frac{\left(B-N_{1}^{\mathrm{C}}\right)}{\left(B-n_{1}^{\mathrm{C}}\right)}\right]+\left(\frac{n_{12}+n_{2}}{N_{2}}\right)^{\mathrm{C}}\left[\frac{\left(B-N_{2}^{\mathrm{C}}\right)}{\left(B-\left(n_{12}+n_{2}\right)^{\mathrm{C}}\right)}\right]-\left(\frac{n_{12}}{N_{2}}\right)^{\mathrm{C}}\left[\frac{\left(B-N_{2}^{\mathrm{C}}\right)}{\left(B-n_{12}^{\mathrm{C}}\right)}\right]
$$

with 


$$
n_{12}=\left\{\frac{1}{B}\left[1+\left(\frac{r_{2}}{1-r_{2}}\right)\left(\frac{1-r_{1}}{r_{1}}\right)\left(B n_{1}^{-\mathrm{C}}-1\right)\right]\right\}^{-1 / \mathrm{C}} .
$$

2.2. Three-stress level

(a) Palmgren-Miner's rule

$$
D=\frac{n_{1}}{N_{1}}+\frac{n_{2}}{N_{2}}+\frac{n_{3}}{N_{3}}
$$

(b) Modified Palmgren-Miner's rule

$$
D=\left(\frac{n_{1}}{N_{1}}+\frac{n_{2}}{N_{2}}+\frac{n_{3}}{N_{3}}\right)^{c}
$$

(c) $\mathrm{H}-\mathrm{H}-\mathrm{I}$

$$
D=\frac{B-N_{1}^{\mathrm{C}}}{B-n_{1}^{\mathrm{C}}}+\left[\frac{B-N_{2}^{\mathrm{C}}}{B-\left(n_{12}+n_{2}\right)^{\mathrm{C}}}-\frac{B-N_{2}^{\mathrm{C}}}{B-n_{12}^{\mathrm{C}}}\right]+\left[\frac{B-N_{3}^{\mathrm{C}}}{B-\left(n_{23}+n_{3}\right)^{\mathrm{C}}}-\frac{B-N_{3}^{\mathrm{C}}}{B-n_{23}^{\mathrm{C}}}\right]
$$

with

$$
n_{23}=\left\{B\left[1-\left(\frac{r_{3}}{r_{2}}\right)\left(1-\frac{\left(n_{12}+n_{2}\right)^{C}}{B}\right)\right]\right\}^{1 / C}
$$

and $n_{12}$ is the same as eqn $(6 \mathrm{~b})$.

(d) $\mathrm{H}-\mathrm{H}-\mathrm{II}$

$$
\begin{aligned}
D=\left(\frac{n_{1}}{N_{1}}\right)^{\mathrm{C}}\left[\frac{\left(B-N_{1}^{\mathrm{C}}\right)}{\left(B-n_{1}^{\mathrm{C}}\right)}\right]+\left(\frac{n_{12}+n_{2}}{N_{2}}\right)^{\mathrm{C}}\left[\frac{\left(B-N_{2}^{\mathrm{C}}\right)}{\left(B-\left(n_{12}+n_{2}\right)^{\mathrm{C}}\right)}\right]-\left(\frac{n_{12}}{N_{2}}\right)^{\mathrm{C}}\left[\frac{\left(B-N_{2}^{\mathrm{C}}\right)}{\left(B-n_{12}^{\mathrm{C}}\right)}\right] \\
+\left(\frac{n_{23}+n_{3}}{N_{3}}\right)^{\mathrm{C}}\left[\frac{B-N_{3}^{\mathrm{C}}}{B-\left(n_{23}+n_{3}\right)^{\mathrm{C}}}\right]-\left(\frac{n_{23}}{N_{3}}\right)^{\mathrm{C}}\left[\frac{B-N_{3}^{\mathrm{C}}}{B-n_{23}^{\mathrm{C}}}\right]
\end{aligned}
$$

with

$$
n_{23}=\left\{\frac{1}{B}\left[1+\left(\frac{r_{3}}{1-r_{3}}\right)\left(\frac{1-r_{2}}{r_{2}}\right)\left(B\left(n_{12}+n_{2}\right)^{-\mathrm{C}}-1\right)\right]\right\}^{-1 / C}
$$

and $n_{12}$ is the same as eqn (7b).

\section{FATIGUE RELIABILITY ANALYSIS}

The fatigue reliability of composite laminates is studied on the basis of the structural reliability theory (Ang and Tang, 1984), which states that a structural system fails to function properly when it reaches a limit state and the probability that the system does not reach the limit state is defined as the reliability of the system. The limit state in terms of $k$ random variables, $x_{1}, x_{2}, \ldots, x_{k}$, may be denoted as

$$
g\left(x_{1}, x_{2}, \cdots, x_{k}\right)=0
$$

The failure probability of this limit state can be written as 


$$
P_{\mathrm{f}}=\int \cdots \int_{g<0} \int f_{x_{1}, x_{2}, x_{k}}\left(x_{1}, x_{2}, \cdots, x_{k}\right) \mathrm{d} x_{1} \cdots \mathrm{d} x_{k}
$$

in which $P_{\mathrm{f}}$ is failure probability, $f_{x_{1}, x_{2} \ldots \ldots x_{k}}(\cdot)$ is the joint probability density function; the integration is performed over the region where $g<0$. The reliability of the system, $P_{s}$, is obtained as

$$
P_{\mathrm{s}}=1-P_{\mathrm{r}}
$$

In view of eqn (3), the limit state equation for fatigue reliability analysis is expressed as

$$
g\left(N_{1}, \cdots, N_{k}\right)=1-D=0 .
$$

Herein only fatigue lives $\left(N_{i}\right)$ for cyclic stresses of constant stress amplitudes are treated as random variables. The limit state equations for the four cumulative damage models of two or three stress levels can be derived from eqns (4)-(11) and written as:

(i) Palmgren-Miner's model

Two-stress level

$$
1-\left[\frac{n_{1}}{N_{2}}+\frac{n_{2}}{N_{2}}\right]=0
$$

Three-stress level

$$
1-\left[\frac{n_{1}}{N_{1}}+\frac{n_{2}}{N_{2}}+\frac{n_{3}}{N_{3}}\right]=0
$$

(ii) Modified Palmgren-Miner's model

Two-stress level

$$
1-\left(\frac{n_{1}}{N_{1}}+\frac{n_{2}}{N_{2}}\right)^{\mathrm{C}}=0
$$

Three-stress level

$$
1-\left(\frac{n_{1}}{N_{1}}+\frac{n_{2}}{N_{2}}+\frac{n_{3}}{N_{3}}\right)^{\mathrm{C}}=0
$$

(iii) $\mathrm{H}-\mathrm{H}-\mathrm{I}$

Two-stress level

$$
1-\left[\frac{B-N_{1}^{\mathrm{C}}}{B-n_{1}^{\mathrm{C}}}+\frac{B-N_{2}^{\mathrm{C}}}{B-\left(n_{12}+n_{2}\right)^{\mathrm{C}}}-\frac{B-N_{2}^{\mathrm{C}}}{B-n_{12}^{\mathrm{C}}}\right]=0
$$

Three-stress level

$$
1-\left[\frac{B-N_{1}^{\mathrm{C}}}{B-n_{1}^{\mathrm{C}}}+\frac{B-N_{2}^{\mathrm{C}}}{B-\left(n_{12}+n_{2}\right)^{\mathrm{C}}}-\frac{B-N_{2}^{\mathrm{C}}}{B-n_{12}^{\mathrm{C}}}+\frac{B-N_{3}^{\mathrm{C}}}{B-\left(n_{23}+n_{3}\right)^{\mathrm{C}}}-\frac{B-N_{3}^{\mathrm{C}}}{B-n_{23}^{\mathrm{C}}}\right]=0 .
$$

(iv) $\mathrm{H}-\mathrm{H}-\mathrm{II}$

Two-stress level 


$$
1-\left\{\left(\frac{n_{1}}{N_{1}}\right)^{\mathrm{C}}\left[\frac{B-N_{1}^{\mathrm{C}}}{B-n_{1}^{\mathrm{C}}}\right]+\left(\frac{n_{12}+n_{2}}{N_{2}}\right)^{\mathrm{C}}\left[\frac{B-N_{2}^{\mathrm{C}}}{B-\left(n_{12}+n_{2}\right)^{\mathrm{C}}}\right]\left(\frac{n_{12}}{n_{2}}\right)^{\mathrm{C}}\left[\frac{B-N_{2}^{\mathrm{C}}}{B-n_{12}^{\mathrm{C}}}\right]\right\}=0
$$

Three-stress level

$$
\begin{aligned}
1-\left\{\left(\frac{n_{1}}{N_{1}}\right)^{\mathrm{C}}\left[\frac{B-N_{1}^{\mathrm{C}}}{B-n_{1}^{\mathrm{C}}}\right]+\left(\frac{n_{12}+n_{2}}{N_{2}}\right)^{\mathrm{C}}\left[\frac{B-N_{2}^{\mathrm{C}}}{B-\left(n_{12}+n_{2}\right)^{\mathrm{C}}}\right]-\left(\frac{n_{12}}{N_{2}}\right)^{\mathrm{C}}\left[\frac{B-N_{2}^{\mathrm{C}}}{B-n_{12}^{\mathrm{C}}}\right]\right. \\
\left.+\left(\frac{n_{23}+n_{3}}{N_{3}}\right)^{\mathrm{C}}\left[\frac{B-N_{2}^{\mathrm{C}}}{B-\left(n_{23}+n_{3}\right)^{\mathrm{C}}}\right]-\left(\frac{n_{23}}{N_{3}}\right)^{\mathrm{C}}\left[\frac{B-N_{3}^{\mathrm{C}}}{B-n_{23}^{\mathrm{C}}}\right]\right\}=0 .
\end{aligned}
$$

It is noted that the above limit state equations can be expressed explicitly in terms of the random variables $N_{1}, N_{2}, \ldots, N_{k}$. The shapes of the limit state equations constructed on the basis of the above cumulative damage models with two stress levels are shown in Fig. 1. It is worth noting that both Palmgren-Miner's and modified Palmgren-Miner's models yield the same limit state equation and, thus, the same reliability as expected. Herein, the fatigue lives $N_{1}, N_{2}, \ldots, N_{k}$ in eqn (15) are assumed to be independent and a direct numerical integration method is adopted to solve eqn (13) for $P_{\mathrm{f}}$. The 2-D problem of Fig. 1(a) is used as an example to illustrate the idea of the present method. The failure region in the fatigue life space is divided into three sub-regions as shown in Fig 2 . The failure probability can then be expressed as the sum of the probabilities over the sub-regions.

$$
P_{\mathrm{f}}=P_{\mathrm{f}_{1}}+P_{\mathrm{f}_{2}}+P_{\mathrm{f}_{3}}
$$

with

$$
\begin{gathered}
P_{\mathrm{f}_{1}}=\int_{0}^{\infty} \int_{0}^{n_{1}} f_{N_{1}}\left(x_{1}\right) f_{N_{2}}\left(x_{2}\right) \mathrm{d} x_{1} \mathrm{~d} x_{2} \\
P_{\mathrm{f}_{2}}=\int_{0}^{\infty} \int_{0}^{n_{2}} f_{N_{1}}\left(x_{1}\right) f_{N_{2}}\left(x_{2}\right) \mathrm{d} x_{1} \mathrm{~d} x_{2}-\int_{0}^{n_{2}} \int_{0}^{n_{1}} f_{N_{1}}\left(x_{1}\right) f_{N_{2}}\left(x_{2}\right) \mathrm{d} x_{1} \mathrm{~d} x_{2}
\end{gathered}
$$

and

$$
P_{\mathrm{f}_{3}}=\int_{n_{1}}^{\infty} \int_{n_{2}}^{N_{2}^{\prime}} f_{N_{1}}\left(x_{1}\right) f_{N_{2}}\left(x_{2}\right) \mathrm{d} x_{1} \mathrm{~d} x_{2}
$$

where $N_{2}^{\prime}$ is determined from the limit state equation $g=0$. In view of the theorem of marginal probability, eqns (25a) and (25b) can be simplified as

$$
P_{f_{1}}=\int_{0}^{n_{1}} f_{N_{1}}\left(x_{1}\right) \mathrm{d} x_{1}
$$

and

$$
P_{f_{2}}=\int_{0}^{n_{2}} f_{N_{2}}\left(x_{2}\right) \mathrm{d} x_{2}-\int_{0}^{n_{2}} f_{N_{2}}\left(x_{2}\right) \mathrm{d} x_{2} \int_{0}^{n_{1}} f_{N_{1}}\left(x_{1}\right) \mathrm{d} x_{1}
$$

The above sub-regional probabilities can be easily and accurately evaluated using either analytical or numerical integration methods. The probability of eqn $(25 \mathrm{c})$, which is the shaded area in Fig. 2, will be approximated as 


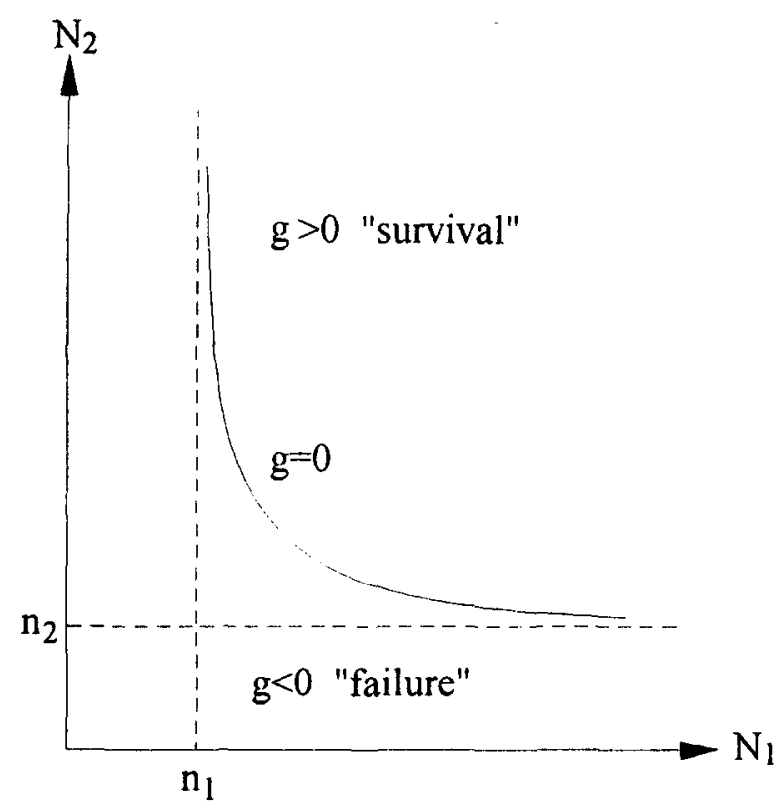

(a) Palmgren-Miner's rule and modified Palmgren-Miner's rule.

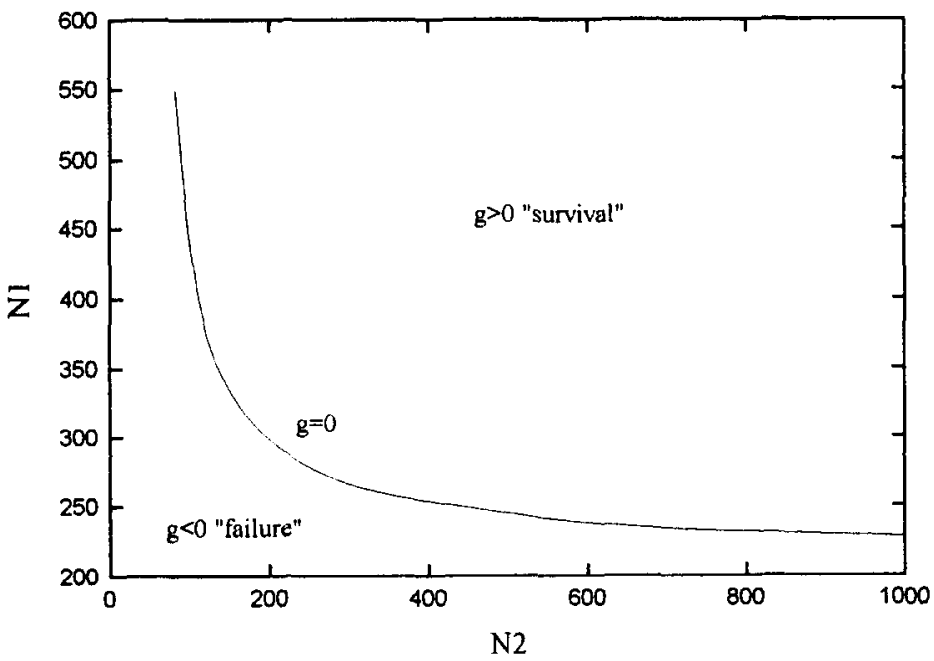

(b) H-H-I $(B=91.6, C=0.306)$

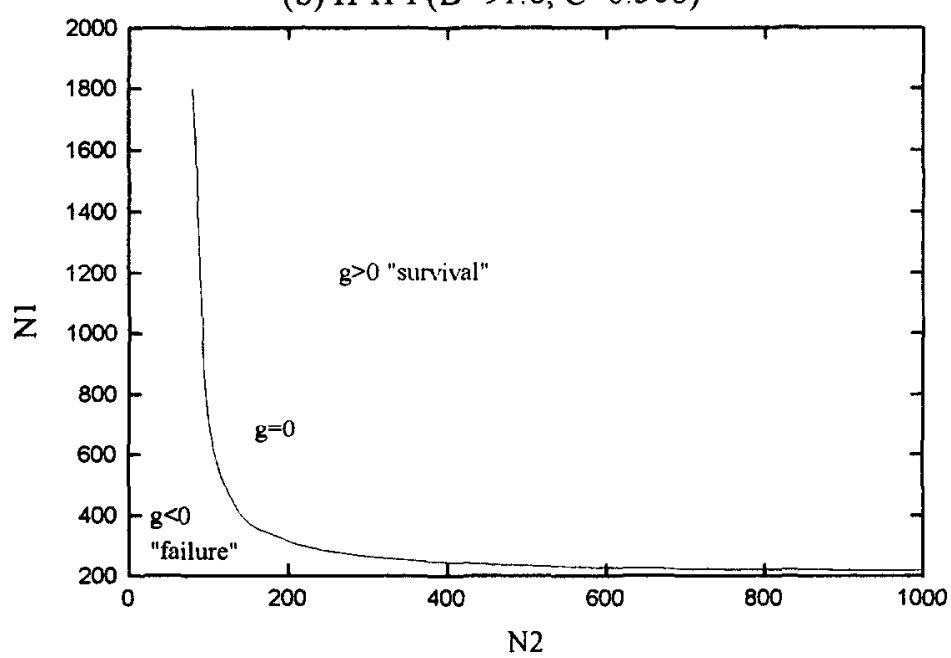

(c) H-H-II $(B=91.6, C=0.306)$

Fig. 1. Fatigue limit state equations with two random variables. 


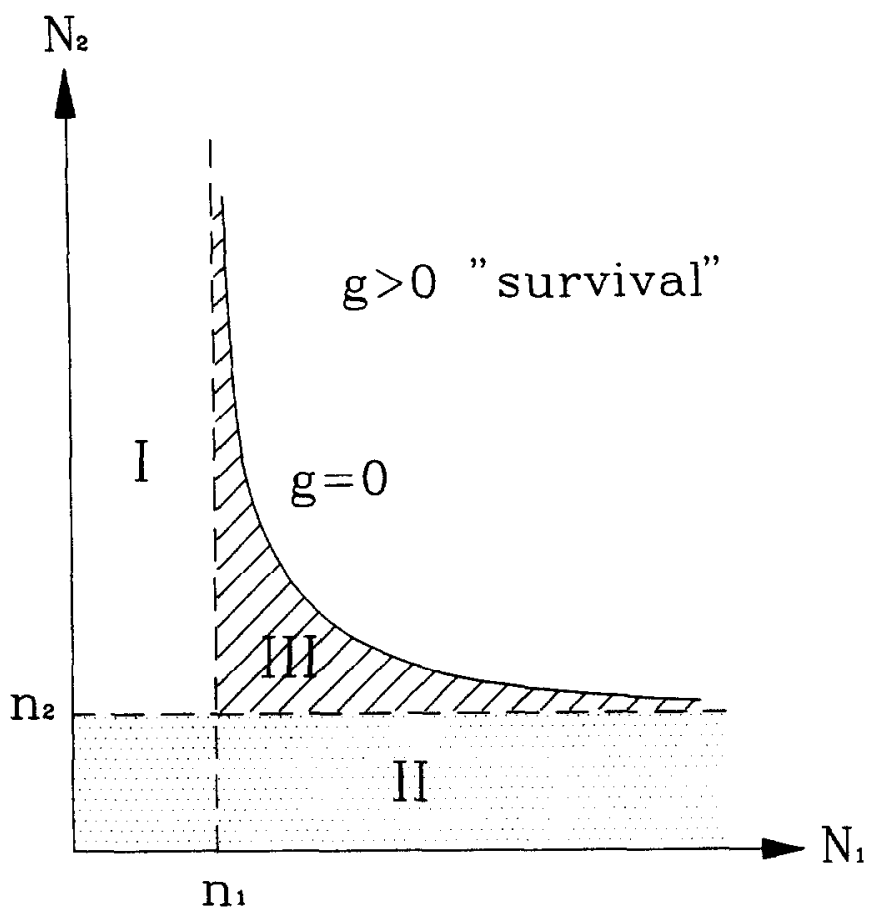

Fig. 2. Sub-regions of failure region.

$$
P_{f_{3}} \cong \int_{n_{1}}^{n_{\max }} \int_{n_{2}}^{N_{2}^{\prime}} f_{N_{1}}\left(x_{1}\right) f_{N_{2}}\left(x_{2}\right) \mathrm{d} x_{1} \mathrm{~d} x_{2}
$$

where $n_{\max }$ is a sufficiently large number beyond which the joint probability of $N_{1}$ and $N_{2}$ is too small to be considered. In numerical integration form, eqn (27) is written as

$$
P_{f_{3}}=\sum_{i=1}^{Q} W_{i}\left\{\sum_{j=1}^{R} C_{i j} f_{N_{1}}\left(x_{1 i}\right) f_{N_{2}}\left(x_{2 j}\right)\right\}
$$

where $W_{i}$, and $C_{i j}$ are weighting factors; $Q$ and $R$ are numbers of integration points ; $x_{1 \mathrm{is}}$ $x_{2 \mathrm{j}}$ are coordinates of integration points in $N_{1}$ and $N_{2}$ directions, respectively. It is noted that $x_{2 j}$ must be in the interval $\left[n_{2}, N_{2}^{\prime}\right]$ where $N_{2}^{\prime}$ is determined by satisfying the limit state equation, i.e. $g\left(x_{\mathrm{li}}, N_{2}^{\prime}\right)=0$. The above procedure can be easily extended to cases containing more than two random variables. For example, the failure probability in 3-D fatigue life space is expressed as

$$
P_{\mathrm{f}}=P_{\mathrm{f}_{1}}+P_{\mathrm{f}_{2}}+P_{\mathrm{f}_{3}}-P_{\mathrm{f}_{1}} P_{\mathrm{f}_{2}}-P_{\mathrm{f}_{2}} P_{\mathrm{f}_{3}}-P_{\mathrm{f}_{3}} P_{\mathrm{r}_{1}}+P_{\mathrm{f}_{1}} P_{\mathrm{f}_{2}} P_{\mathrm{f}_{3}}+P_{\mathrm{f}_{4}}
$$

with

$$
P_{f_{i}}=\int_{0}^{n_{i}} f_{N_{i}}\left(x_{i}\right) \mathrm{d} x_{i} \quad(i=1,2,3)
$$

and

$$
P_{f_{4}}=\int_{n_{1}}^{\infty} \int_{n_{2}}^{\infty} \int_{n_{3}}^{N_{3}^{\prime}} f_{N_{1}}\left(x_{1}\right) f_{N_{2}}\left(x_{2}\right) f_{N_{3}}\left(x_{3}\right) \mathrm{d} x_{1} \mathrm{~d} x_{2} \mathrm{~d} x_{3}
$$

where $N_{3}^{\prime}$ is determined by satisfying the limit state equation, i.e. $g\left(x_{1}, x_{2}, N_{3}^{\prime}\right)=0$.

Equation (31) expressed in numerical integration form is written as 


$$
P_{\mathrm{f}_{4}}=\sum_{i=1}^{Q} W_{i}\left\{\sum_{j=1}^{R} C_{i j}\left[\sum_{m=1}^{M} H_{i j m} f_{N_{1}}\left(x_{1 i}\right) f_{N_{2}}\left(x_{2 j}\right) f_{N_{3}}\left(X_{3 m}\right)\right]\right\}
$$

where $Q, R, M$ are numbers of integration points; $W_{i}, C_{i j}, H_{i j m}$ are weighting factors ; $x_{1 i}$, $x_{2 j}, x_{3 m}$ are coordinates of integration points in $N_{1}, N_{2}$ and $N_{3}$ directions, respectively.

\section{EXPERIMENTAL FATIGUE LIFE DATA}

Fatigue life tests of $\left[45^{\circ} /-45_{2}^{\circ} / 45^{\circ}\right]_{s}$ graphite/epoxy laminates subjected to cyclic stresses of constant amplitudes and spectrum stresses were previously performed under the isothermal condition using a 10-ton Instron testing machine. A detailed description of the experimental procedure was reported in the literature (Kam et al., 1997). The mean values of the experimental fatigue lives for constant stress levels, $r=0.95,0.9$ and 0.85 were 243.8 , 648.7 and 6485.7 cycles, respectively. The fatigue life cycle data for each of the cyclic stress of constant amplitude were also fitted by either lognormal or Weibull distributions. It has been shown that, in general, both lognormal and Weibull distributions can yield good fit of the test data. The probability density functions of lognormal and Weibull are expressed, respectively, as:

lognormal distribution

$$
f_{N}(n)=\frac{1}{n \sqrt{2 \pi} \xi} \exp \left[-\left(\frac{\ln (n)-\lambda}{\xi}\right)^{2}\right]
$$

where $f_{N}(n) \geqslant 0, n>0 ; \lambda$ is mean of natural logarithm of cycles to failure; and $\xi$ is standard deviation of natural logarithm of cycles to failure.

Weibull distribution

$$
f_{N}(n)=\frac{\alpha}{\theta}\left(\frac{n}{\theta}\right)^{\alpha-1} \exp \left[-\left(\frac{n}{\theta}\right)^{\alpha}\right]
$$

where $f_{N} \geqslant 0, n \geqslant 0 ; \alpha$ is shape parameter, $\theta$ is scale parameter. The statistics, mean $(\bar{N})$ and coefficient of variation (c.o.v.), and parameters of fatigue life distributions for the three constant stress levels are listed in Table 1. The mean lives of the laminates at various stress levels were used to determine the constants, $B=91.6$ and $c=0.306$, in the Hwang-Han's models of eqns (6) and (7) via the least-square method. Fatigue life tests of the $\left[45^{\circ} /-45_{2}^{\circ} / 45^{\circ}\right]_{s}$ specimens subjected to spectrum stresses of two or three stress levels were conducted and the numbers of cycles at different stress levels were recorded for the following cases: (i) record the number of cycles $n_{2}$ for stress level $r_{2}=0.95$ after the specimens have been tested for $n_{1}=200$ at the stress level $r_{1}=0.9$. The mean life at stress level $r_{2}=0.95$ is $\bar{n}_{2}=200.6 \mathrm{cs}$; (ii) record the number of cycles $n_{2}$ for stress level $r_{2}=0.9$ after the specimens have been tested for $n_{1}=80$ at the stress level $r_{1}=0.95$. The mean life at stress level $r,=0.9$ is $\bar{n}_{2}=617 \mathrm{cs}$; (iii) record the number of cycles $n_{3}$ for $r_{3}=0.95$ after the specimens have been tested for $n_{1}=1500$ and $n_{2}=150$ at $r_{1}=0.85$ and $r_{2}=0.9$, respectively. The mean life at stress level $r_{3}=0.95$ is $\bar{n}_{3}=122.13 \mathrm{cs}$; (iv) record the number of cycles $n_{3}$ for $r_{3}=0.85$

\begin{tabular}{|c|c|c|c|c|c|c|}
\hline \multirow[b]{2}{*}{$r$} & \multicolumn{4}{|c|}{ Lognormal } & \multicolumn{2}{|c|}{ Weibull } \\
\hline & $\lambda$ & $\xi$ & $\bar{N}$ & $c . o . v .=\sigma / \bar{N}$ & $\alpha$ & $\Theta$ \\
\hline 0.85 & 8.59917 & 0.64685 & 6690.06 & 0.7208 & 1.64566 & 7420.208 \\
\hline 0.90 & 6.41836 & 0.39224 & 662.165 & 0.4077 & 2.92501 & 729.77 \\
\hline 0.95 & 5.41079 & 0.46561 & 249.43 & 0.4920 & 2.38782 & 277.653 \\
\hline
\end{tabular}
after the specimens have been tested for $n_{1}=80$ and $n_{2}=150$ at $r_{1}=0.95$ and $r_{2}=0.9$,

Table 1. Statistics of fatigue life at various stress levels fitted by different probability distributions 
Table 2. Statistics of fatigue life distributions under various spectrum stresses

\begin{tabular}{|c|c|c|c|c|c|}
\hline & \multirow[b]{2}{*}{ Case } & \multicolumn{2}{|c|}{ Lognormal } & \multicolumn{2}{|c|}{ Weibull } \\
\hline & & Median & c.o.v. & $\alpha$ & $\Theta$ \\
\hline (i) & $\begin{array}{l}r_{1}=0.90 \\
r_{2}=0.95\end{array}$ & 170.33 & 0.6649 & 1.64252 & 232.695 \\
\hline (ii) & $\begin{array}{l}r_{1}=0.95 \\
r_{2}=0.90\end{array}$ & 484.03 & 0.85925 & 1.38578 & 701.873 \\
\hline (iii) & $\begin{array}{l}r_{1}=0.85 \\
r_{2}=0.90 \\
r_{3}=0.95\end{array}$ & 91.03 & 0.99809 & 1.11716 & 143.009 \\
\hline (iv) & $\begin{array}{l}r_{1}=0.95 \\
r_{2}=0.90 \\
r_{3}=0.85\end{array}$ & 2293.72 & 0.83382 & 1.43808 & 3275.923 \\
\hline
\end{tabular}

Table 3. Fatigue lives with reliability 0.9 under various spectrum stresses

\begin{tabular}{lccccc}
\hline Spectrum stress & \multicolumn{3}{c}{$n_{2}$} & $n_{3}$ & Weibull \\
\hline$r_{1}=0.90, r_{2}=0.95$ & $n_{1}$ & Lognormal & Weibull & Lognormal & - \\
$r_{1}=0.95, r_{2}=0.90$ & 200 & 72.65 & 59.121 & - & - \\
$r_{1}=0.85, r_{2}=0.90, r_{3}=0.95$ & 80 & 160 & 138.36 & - & - \\
$r_{1}=0.95, r_{2}=0.90, r_{3}=0.85$ & 1500 & 150 & 150 & 25.33 & 19.078 \\
\hline
\end{tabular}

Table 4. Fatigue damages of composite laminate under different spectrum stresses

\begin{tabular}{|c|c|c|c|c|c|}
\hline \multirow[b]{2}{*}{ Spectrum stress } & \multirow[b]{2}{*}{$\begin{array}{l}\text { Number of applied } \\
\text { stress cycles }\end{array}$} & \multicolumn{4}{|c|}{ Fatigue Damage $D$ and error $(\%)$} \\
\hline & & $\begin{array}{l}\text { Palmgren- } \\
\text { Miner }\end{array}$ & $\begin{array}{c}\text { Modified } \\
\text { Palmgren-Miner }\end{array}$ & $\mathrm{H}-\mathrm{H}-\mathrm{I}$ & $\mathbf{H}-\mathrm{H}-\mathrm{II}$ \\
\hline 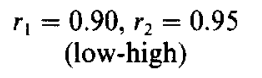 & $n_{1}=200, \bar{n}_{2}=200.6$ & $\begin{array}{l}1.1310^{*} \\
(13.1) \dagger\end{array}$ & $\begin{array}{l}1.0384 \\
(3.84)\end{array}$ & $\begin{array}{l}0.9999 \\
(0.01)\end{array}$ & $\begin{array}{l}1.0389 \\
(3.89)\end{array}$ \\
\hline 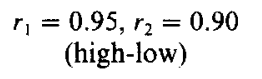 & $n_{1}=80, \bar{n}_{2}=617$ & $\begin{array}{l}1.2792 \\
(27.92)\end{array}$ & $\begin{array}{l}1.0784 \\
(7.84)\end{array}$ & $\begin{array}{l}1.0098 \\
(0.98)\end{array}$ & $\begin{array}{l}1.0877 \\
(8.77)\end{array}$ \\
\hline $\begin{array}{l}r_{1}=0.85, r_{2}=0.90 \\
r_{3}=0.95 \text { (low-high) }\end{array}$ & $\begin{array}{c}n_{1}=1500, n_{2}=150 \\
\tilde{n}_{3}=122.13\end{array}$ & $\begin{array}{r}0.9634 \\
(3.66)\end{array}$ & $\begin{array}{l}0.9887 \\
(1.13)\end{array}$ & $\begin{array}{l}0.9913 \\
(0.87)\end{array}$ & $\begin{array}{l}0.9773 \\
(2.27)\end{array}$ \\
\hline $\begin{array}{l}r_{1}=0.95, r_{2}=0.90 \\
r_{3}=0.85 \text { (high-low) }\end{array}$ & $\begin{array}{c}n_{1}=80, n_{2}=150 \\
\bar{n}_{3}=2958.07\end{array}$ & $\begin{array}{r}1.0154 \\
(1.54)\end{array}$ & $\begin{array}{l}1.0047 \\
(0.47)\end{array}$ & $\begin{array}{l}1.0168 \\
(1.68)\end{array}$ & $\begin{array}{l}1.0177 \\
(1.77)\end{array}$ \\
\hline
\end{tabular}

* Cumulative fatigue damage $D$.

$\dagger$ Percentage error $=|(1.0-D) /(1.0)| \%$.

respectively. The mean life at stress level $r_{3}=0.85$ is $\bar{n}_{3}=2958.07 \mathrm{cs}$. The fatigue life data were also fitted by either lognormal or Weibull distributions. Again it has been shown that, in general, both lognormal and Weibull distributions can yield good fit of the test data. The statistics and parameters of the probability distributions are given in Table 2 . It is noted that the variations of fatigue lives for the above cases are very large (coefficient of variations may be greater than $66 \%$ ). The residual fatigue lives of the laminates under various spectrum stresses with reliability, say, $P_{\mathrm{s}}=0.9$ can be determined directly from their life distributions and the results are listed in Table 3 . If the experimentally determined mean fatigue lives at different stress levels are used in solving eqns (4)-(11), the cumulative damages of the laminates under various spectrum stresses based on different cumulative damage models can be evaluated as shown in Table 4. It is noted that in general the cumulative damage models of modified Palmgren-Miner's rule, $\mathrm{H}-\mathrm{H}-\mathrm{I}$ and $\mathrm{H}-\mathrm{H}-\mathrm{II}$ can yield reasonably good results if a deterministic approach is adopted. In particular, the errors of the fatigue damage predicted by the $\mathrm{H}-\mathrm{H}-\mathrm{I}$ are less than $2 \%$ for all of the cases under consideration. 
Table 5. Fatigue reliabilities evaluated by different methods

\begin{tabular}{cccccc}
\hline $\begin{array}{c}\text { Probability } \\
\text { distribution }\end{array}$ & $\begin{array}{c}\text { Spectrum } \\
\text { stress }\end{array}$ & $\begin{array}{c}\text { Fatigue } \\
\text { model }\end{array}$ & Present (I) & Monte-Carlo (II) & $\begin{array}{c}\text { Rifference } \\
|(\mathrm{I}-\mathrm{II}) /(\mathrm{II})| \%\end{array}$ \\
\hline Lognormal & $r_{1}=0.95, r_{2}=0.90$ & Miner & 0.9254378 & 0.9254714 & 0.004 \\
Weibull & $n_{1}=80, n_{2}=160$ & H-H-II & 0.9226745 & 0.9229162 & 0.026 \\
& $r_{1}=0.95, r_{2}=0.90$ & Miner & 0.9239201 & 0.9229764 & 0.1022 \\
\hline
\end{tabular}

\section{RESULTS AND DISCUSSION}

The accuracy of the proposed numerical integration technique is first studied by comparing results obtained by the present method for some fatigue limit state equations with those obtained via Monte-Carlo method. Subroutine RNLNL of the IMSL Mathematical Package (1989) is used in the reliability simulation for lognormal variates and subroutine RNWIB and SSCAL for Weibull variates. Over 5000 sets of simulation for each fatigue limit state equation composed of two random variables are performed. The probability distributions given in Table 1 are used in the reliability analysis and Monte-Carlo simulation. The results obtained by the two methods for Palmgren-Miner's rule and $\mathrm{H}-\mathrm{H}-\mathrm{II}$ model are listed in Table 5 for comparison. It is noted that the insignificant differences between the two methods verify the accuracy of the proposed technique. The feasibility of the numerical integration technique in fatigue reliability prediction of composite materials under spectrum stress is then studied using the test data given in the previous section. Using the probability distributions of fatigue lives at different constant stress levels given in Table 1 , various limit state equations and the residual lives listed in Table 3, the theoretical reliabilities of the laminates under different spectrum stresses are evaluated via the present method. The theoretical predictions are listed in Tables 6 and 7 in comparison with the target reliability (0.9) obtained from the experimental data. It has been shown that irrespective of stress sequence and probability distribution, the theoretical approach can yield reasonably good results for the laminates provided that fatigue damages are modeled by PalmgrenMiner's rule or $\mathrm{H}-\mathrm{H}-\mathrm{II}$. On the contrary, $\mathrm{H}-\mathrm{H}-\mathrm{I}$ cannot yield consistent accuracy in fatigue reliability prediction and, thus, it may not be applicable for fatigue reliability analysis of composite laminates. It is also worth noting that stress sequence effect is not obvious because the accuracy of the results predicted by the present approach does not have any direct correlation to the sequence of applied stress levels.

To further demonstrate the advantages of using the present approach for fatigue rcliability analysis, the fatigue reliabilities of the above cases predicted by the modified $\beta$ method (Kam et al., 1997) are listed in Tables 8 and 9 in comparison with those obtained by the present method. The negative signs ahead of the percentage differences between the experimental and theoretical fatigue lives in Tables 8 and 9 indicate that the theoretical fatigue reliabilities are less than the experimental ones. It is noted that the overall performance of the present method is better than that of the modified $\beta$-method. In view of the target reliability, the present method may yield results on the safe side while the modified $\beta$-method may do the opposite and ovcrestimate the fatigue reliability. For instance, for the case of $r_{1}=0.9$ and $r_{2}=0.95$ based on Palmgren-Miner's rule in Table 8, the reliabilities predicted by the present method and the modified $\beta$-method are 0.895 and 0.919 , respectively. For cases where both the present method and the modified $\beta$-method overestimate the fatigue reliability of the laminates, the present method can always yield values closer to the experimental results than the modified $\beta$-method. For example, for the case of $r_{1}=0.9$ and $r_{2}=0.95$ based on Palmgren-Miner's rule in Table 9, the reliabilities predicted by the present method and the modified $\beta$-method are 0.901 and 0.937 , respectively.

\section{CONCLUSIONS}

A numerical integration technique was developed for evaluating fatigue reliability of composite laminates subjected to spectrum stresses. The accuracy of the proposed method 
Fatigue reliability evaluation for composite laminates
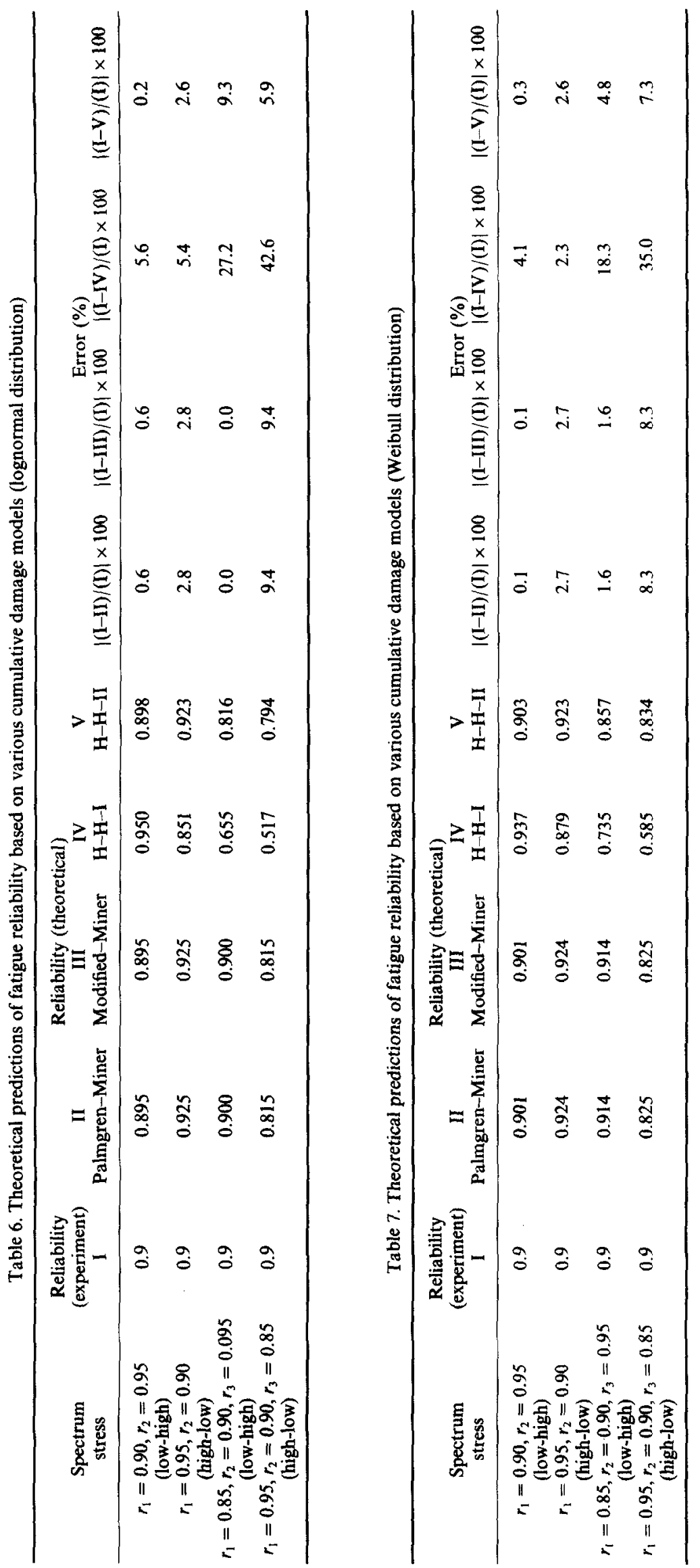
Table 8 . Fatigue reliabilities predicted by different methods using Lognormal distributions for random variables

\begin{tabular}{|c|c|c|c|c|c|c|c|c|c|}
\hline \multirow{3}{*}{$\begin{array}{l}\text { Spectrum } \\
\text { stress }\end{array}$} & \multirow{3}{*}{$\begin{array}{l}\text { Reliability } \\
\text { (experiment) }\end{array}$} & \multicolumn{8}{|c|}{ Reliability (theoretical) } \\
\hline & & \multicolumn{2}{|c|}{ Palmgren-Miner } & \multicolumn{2}{|c|}{ Modified-Miner } & \multicolumn{2}{|c|}{ H-H-I } & \multicolumn{2}{|c|}{ H-H-II } \\
\hline & & $I^{(a)}$ & $\mathrm{II}^{(\mathrm{b})}$ & I & II & I & II & I & II \\
\hline $\begin{array}{c}r_{1}=0.9, r_{2}=0.95 \\
\text { (low-high) }\end{array}$ & 0.9 & $\begin{array}{c}0.895 \\
(-0.6)^{*}\end{array}$ & $\begin{array}{l}0.919 \\
(2.1)\end{array}$ & $\begin{array}{r}0.895 \\
(-0.6)\end{array}$ & $\begin{array}{l}0.919 \\
(2.1)\end{array}$ & $\begin{array}{c}0.950 \\
(5.6)\end{array}$ & $\begin{array}{l}0.965 \\
(7.2)\end{array}$ & $\begin{array}{l}0.898 \\
(-0.2)\end{array}$ & $\begin{array}{l}0.923 \\
(2.6)\end{array}$ \\
\hline $\begin{aligned} r_{1}= & 0.95, r_{2}=0.90 \\
& \text { (high-low) }\end{aligned}$ & 0.9 & $\begin{array}{r}0.925 \\
(2.8)\end{array}$ & $\begin{array}{l}0.939 \\
(4.3)\end{array}$ & $\begin{array}{l}0.925 \\
(2.8)\end{array}$ & $\begin{array}{l}0.939 \\
(4.3)\end{array}$ & $\begin{array}{l}0.851 \\
(-5.4)\end{array}$ & $\begin{array}{l}0.863 \\
(-4.1)\end{array}$ & $\begin{array}{l}0.923 \\
(2.6)\end{array}$ & $\begin{array}{r}0.937 \\
(4.1)\end{array}$ \\
\hline $\begin{array}{c}r_{1}=0.85, r_{2}=0.90 \\
r_{3}=0.95\end{array}$ & 0.9 & 0.900 & 0.916 & 0.900 & 0.916 & 0.655 & 0.964 & 0.816 & 0.922 \\
\hline (low-high) & & $(0.0)$ & (1.8) & $(0.0)$ & $(1.8)$ & $(-27.2)$ & $(7.1)$ & $(-9.3)$ & (2.4) \\
\hline $\begin{array}{c}r_{1}=0.95, r_{2}=0.90, \\
r_{2}=0.85\end{array}$ & 0.9 & 0.815 & 0.863 & 0.815 & 0.863 & 0.517 & 0.492 & 0.794 & 0.847 \\
\hline (high-low) & & $(-9.4)$ & $(-4.1)$ & $(-9.4)$ & $(-4.1)$ & $(-42.6)$ & $(-45 . ?$ & $-11.8)$ & $-5.9)$ \\
\hline
\end{tabular}

(a) Present method.

(b) Modified $\beta$-method.

* Percentage different between experimental and theoretical fatigue lives.

Table 9. Fatigue reliabilities predicted by different methods using Weibull distributions for random variables

\begin{tabular}{|c|c|c|c|c|c|c|c|c|c|}
\hline \multirow{3}{*}{$\begin{array}{l}\text { Spectrum } \\
\text { stress }\end{array}$} & \multirow{3}{*}{$\begin{array}{c}\text { Reliability } \\
\text { (experiment) }\end{array}$} & \multirow{3}{*}{\multicolumn{2}{|c|}{$\underset{I^{(a)}}{\text { Palmgren-Miner }}$ II $^{(\mathrm{b})}$}} & \multicolumn{4}{|c|}{ Reliability (theoretical) } & \multirow{2}{*}{\multicolumn{2}{|c|}{$\mathrm{H}-\mathrm{H}-\mathrm{II}$}} \\
\hline & & & & \multicolumn{2}{|c|}{ Modified-Miner } & \multicolumn{2}{|c|}{ H-H-I } & & \\
\hline & & & & I & II & I & II & 1 & II \\
\hline$r_{1}=\begin{array}{c}0.90, r_{2}=0.95 \\
(\text { low-high })\end{array}$ & 0.9 & $\begin{array}{l}0.901 \\
(0.1)^{*}\end{array}$ & $\begin{array}{l}0.937 \\
(4.1)\end{array}$ & $\begin{array}{l}0.901 \\
(0.1)\end{array}$ & $\begin{array}{l}0.937 \\
(4.1)\end{array}$ & $\begin{array}{l}0.937 \\
(4.1)\end{array}$ & $\begin{array}{l}0.968 \\
(7.6)\end{array}$ & $\begin{array}{l}0.903 \\
(0.3)\end{array}$ & $\begin{array}{l}0.939 \\
(4.3)\end{array}$ \\
\hline $\begin{aligned} r_{1}= & 0.95, r_{2}=0.90 \\
& \text { (high-low) }\end{aligned}$ & 0.9 & $\begin{array}{l}0.924 \\
(2.7)\end{array}$ & $\begin{array}{c}0.953 \\
(5.9)\end{array}$ & $\begin{array}{l}0.924 \\
(2.7)\end{array}$ & $\begin{array}{c}0.953 \\
(5.9)\end{array}$ & $\begin{array}{l}0.879 \\
(-2.3)\end{array}$ & $\begin{array}{l}0.907 \\
(0.8)\end{array}$ & $\begin{array}{l}0.923 \\
(2.6)\end{array}$ & $\begin{array}{l}0.951 \\
(5.7)\end{array}$ \\
\hline $\begin{array}{c}r_{1}=0.85, r_{2}=0.90 \\
r_{3}=0.95\end{array}$ & 0.9 & 0.914 & 0.937 & 0.914 & 0.937 & 0.735 & 0.982 & 0.857 & 0.940 \\
\hline (low-high) & & $(1.6)$ & $(4.1)$ & (1.6) & $(4.1)$ & $(-18.3)$ & $(9.1)$ & $(-4.8)$ & (4.4) \\
\hline $\begin{array}{c}r_{1}=0.95, r_{2}=0.90, \\
r_{3}=0.85\end{array}$ & 0.9 & 0.825 & 0.903 & 0.825 & 0.903 & 0.585 & 0.644 & 0.834 & 0.894 \\
\hline (high-low) & & $(-8.3)$ & $(0.3)$ & $(-8.3)$ & $(0.3)$ & $(-35.0)$ & $(-28.4)$ & $(-7.3)$ & $(-0.7)$ \\
\hline
\end{tabular}

(a) Present method.

(b) Modified $\beta$-method.

* Percentage different between experimental and theoretical fatigue lives.

in fatigue reliability prediction was validated by Monte-Carlo method and existing experimental data. The suitability of several cumulative damage models in predicting fatigue damage and reliability of graphite/epoxy $\left[45^{\circ} /-45_{2}^{\circ} / 45^{\circ}\right]_{\mathrm{s}}$ laminates was also studied. It was found that modified Palmgren-Miner's rule, Hwang-Han's model I and II could yield reasonably good results on cumulative damage if a deterministic fatigue analysis was performed while Palmgren-Miner's rule, modified Palmgren-Miner's rule and HwangHan's model II could yield reasonably good results on fatigue reliability of composite materials if a probabilistic approach was adopted. A comparison between the present method and the modified $\beta$-method in fatigue reliability prediction was made. It has been shown that the present method is more suitable for fatigue reliability prediction than the modified $\beta$-method.

Acknowledgement-This research was supported by the National Science Council of the Republic of China under Grant-no NSC 85-2212-E009-016. Their support is gratefully acknowledged.

\section{REFERENCES}

Ang, A. H-S. and Tang, W. H (1984) Probability Concepts in Engineering Planning and Design, Vol. II. RainbonBridge.

Collins, J. A. (1981) Failure of Materials in Mechanical Design. Wiley, New York.

Han, K. S. and Hamddi, M. (1983) Fatigue life scattering of RP/CI. 38th Annual RP/CI Conference, SPI.

IMSL User's Mannual (1989) IMSL Incorporation, Houston, TX.

Johnsen, S. E. J. and Doner, M. (1981) A statistical simulation model of Miner's rule. Journal of Engineering

Materials and Technology, 103, 113-117. 
Kam, T. Y., Tsai, S. Y. and Chu, K. H. (1997) Fatigue reliability analysis of composite laminates under spectrum stress. Journal of Solids and Structures, 34, 1441-1461.

Radhakrishnan, K. (1984) Fatigue and reliability evaluation of unnotched carbon epoxy laminates. Journal of Composite Materials, 18, 21-31.

Yang, J. N. and Du, S. (1983) An exploratory study into the fatigue of composites under spectrum loading. Journal of Composite Materials, 17, 551-526.

Yang, J. N., Lee, L. J. and Sheu, D. Y. (1992) Modulus reduction and fatigue damage of matrix dominated composite laminates. Journal of Composite Structures, 21, 91-100. 